\title{
Quantitative evaluation of partial deletions of the DAZ gene cluster
}

\author{
G. LETIZIA D'AMICO ${ }^{1}$, DANIELA DI BENEDETTO ${ }^{1}$, FRANCA M. PEZZINO ${ }^{1,2}$, VINCENZA GIUFFRIDA ${ }^{1,2}$, \\ MASSIMO LIBRA ${ }^{2}$, MARCO FICHERA ${ }^{4}$, GRAZIA MAUCERI ${ }^{1}$, GIANCARLO RAPPAZZO ${ }^{3}$, \\ ROSARIO D'AGATA ${ }^{1}$, ENZO VICARI ${ }^{1}$, SALVATORE TRAVALI ${ }^{2 *}$ and ALDO E. CALOGERO ${ }^{*}$

\begin{abstract}
${ }^{1}$ Section of Endocrinology, Andrology and Internal Medicine, Master in Andrological and Human Reproduction Sciences, and ${ }^{2}$ Section of Clinical Pathology and Molecular Oncology, Department of Biomedical Sciences, ${ }^{3}$ Department of Animal Biology, University of Catania, Catania; ${ }^{4}$ Istituto Oasi Maria S.S., Troina (EN), Italy
\end{abstract}

Received November 22, 2005; Accepted January 3, 2006

\begin{abstract}
Partial deletions of the DAZ gene cluster are thought to cause spermatogenesis impairment. The presence of homologous copies of this gene in the Y chromosome does not allow PCR to be used for the identification of this abnormality. Hence, sequence family variants (SFV), following amplification of sY581, sY587 and sY586 and subsequent enzymatic digestion with Sau3A, DraI and TaqI, respectively, and the dual fiber fluorescence in situ hybridization (FISH) have been used to this aim. However, SFV is not always able to identify single DAZ gene copy deletions. We report a quantitative real-time PCR application to evaluate partial deletions of the DAZ gene cluster. To accomplish this, we designed a probe on exon 6 of the DAZ gene which is repeated 3 times in DAZ1, once in DAZ2 and DAZ3 and twice in DAZ4. Five normozoospermic healthy men (C1-C5) having 4 DAZ gene copies by SFV were selected. Fiber-FISH confirmed this outcome in $\mathrm{C} 1-\mathrm{C} 4$, but not in $\mathrm{C} 5$ who had an incomplete DAZ gene cluster. The men underwent then quantitative real-time PCR and C1 was arbitrarily selected as calibrator for the calculation of the DAZ gene signals because of the lowest variation in the threshold cycles. Real-time PCR identified 7.2 \pm 0.05 signals in C2-C4 and $5.4 \pm 0.05$ signals in $\mathrm{C} 5$. The overall coefficient of variation was $1.4 \pm 0.2 \%$. The loss of two signals in this subject may
\end{abstract}

Correspondence to: Professor Aldo E. Calogero, Sezione di Endocrinologia, Andrologia e Medicina Interna, Dipartimento di Scienze Biomediche, Università di Catania, Ospedale Garibaldi, Piazza S. Maria di Gesù, I-95123 Catania, Italy

E-mail: acaloger@unict.it

Professor Salvatore Travali, Sezione di Patologia Clinica ed Oncologia Molecolare, Dipartimento di Scienze Biomediche, Università di Catania, Via Androne 87, I-95124 Catania, Italy

E-mail: stravali@unict.it

${ }^{*}$ Contributed equally

Key words: DAZ gene, spermatogenesis, Y chromosome relate to a deletion of both DAZ2 and DAZ3 or of DAZ4 gene. Since SFV showed clearly the presence of DAZ2, it may be hypothesized that C5 lacks DAZ4. In conclusion, these data suggested that quantitative real-time PCR seems to be an effective and reproducible technique that can be used to study the DAZ gene cluster. In addition, the probe chosen for this approach may give indication on the DAZ gene copy deleted.

\section{Introduction}

The human Y chromosome, the smallest chromosome in humans, contains about 27 genes which have been shown to be necessary for male sexual differentiation and spermatogenesis $(1,2)$. Some of them are present in a single copy, whereas others are members of multigenic families. Some proteins encoded by these genes have a ubiquitous expression, others are expressed prevalently or exclusively at the testicular level (3-6), but their function during spermatogenesis remains to be fully established.

Clinical evidence has accumulated showing that microdeletions of the long arm of the $\mathrm{Y}$ chromosome (Yq) are associated with oligozoospermia or azoospermia and, therefore, this $\mathrm{Yq}$ tract has been named azoospermia factor (AZF) (for review see ref. 7). Vogt and collaborators (8) reported that $\mathrm{Yq}$ microdeletions cluster in three distinct subregions named $\mathrm{AZFa}, \mathrm{AZFb}$ and AZFc located in the proximal, central and distal segments of $\mathrm{Yq} 11$. AZFa and $\mathrm{AZFb}$ microdeletions are associated with a specific testicular histological picture, whereas AZFc microdeletions are associated with a variable testicular pathology (9).

The AZFc region is more frequently deleted in men with spermatogenic failure. This region contains several gene families that are expressed exclusively or predominantly in the testis. The best characterized gene family within this region is the deleted in azoospermia gene family (DAZ) (10) which is present in four nearly identical copies, arranged in two clusters with head-to-head orientation (11). Since this structural conformation does not allow PCR gene amplification, to identify partial deletions of the DAZ gene cluster different methodological approaches need to be developed. 
Sequence family variants (SFV) consisting of amplification of sY581, sY587 and sY586 followed by digestion with Sau3A, DraI and TaqI, respectively, has been utilized to identify partial deletions of the DAZ gene cluster in patients with spermatogenic impairment (12). However, SFV using only these three sequence tagged sites (STS) is not able to identify single DAZ gene copy deletions. Indeed, the lack of DAZ1 can not be ascertained because sY581 amplification followed by Sau3A digestion distinguishes only right from left genes in both clusters; sY587 amplification followed by DraI digestion does not distinguish DAZ1 versus DAZ2 deletion; and sY586 amplification followed by TaqI digestion identifies only the deletion of DAZ2.

Therefore, we have developed a different methodological approach to study partial deletions of the DAZ gene cluster. In this study, we report a quantitative real-time PCR application suitable to evaluate partial deletions of the DAZ gene cluster in 5 normozoospermic men (C1-C5) who were also examined by SFV and fiber fluorescence in situ hybridization (FISH).

\section{Materials and methods}

Patient selection. Five healthy men aged $37.4 \pm 1.8$ years (mean \pm SEM) with normal sperm density, motility and morphology, were selected for the study. The protocol was approved by the Institutional Review Board and an informed written consent was obtained from each patient. They had no previous history of cryptorchidism, varicocele, exposure to environmental and/or workplace gonadotoxins. Physical examination showed no gynecomastia and a testicular volume ranging from 15 to $20 \mathrm{ml}$. Laboratory testing showed normal LH, FSH, testosterone, 17ß-estradiol and prolactin serum levels, 46,XY karyotype and normal AZF region, as examined with the following STS markers: sY87, sY743, DBY, sY128, sY129, sY130, sY132, sY134, sY143, sY1196, sY153, sY147, sY243, sY639, sY14, as previously reported (13).

Sequence family variants. SFV was performed by amplifying sY581 which is located in intron 3 of the DAZ gene, sY586 located in intron 6 and sY587 located in intron 10, as previously reported (12).

PCR primers and conditions utilized are those described in GenBank (accession numbers: G63906, G63907 and G63908, respectively). PCR products were analyzed by restriction enzyme digestion according to the manufacturer's instructions.

Digestion of sY581 with Sau3A produces two fragments of 189 and $63 \mathrm{bp}$ in DAZ1 and DAZ4 and three fragments of $130,59,63$ bp in DAZ2 and DAZ3. Digestion of sY586 with TaqI produces two fragments of $184,117 \mathrm{bp}$ in DAZ1, DAZ3 and DAZ4, while in DAZ2 the $301 \mathrm{bp}$ amplification product remains undigested. Digestion of sY587 with DraI produces four fragments of 122, 73, 49, 26 bp in DAZ1 and DAZ2 and three fragments of $195,49,26$ bp in DAZ3 and DAZ4. The digestion products were run on $12 \%$ acrylamide-bisacrylamide gel electrophoresis and visualized by silver staining.

Fiber-FISH. Extended chromatin fibers were prepared as reported (14). Briefly, lymphocytes were fixed in methanol: acetic acid (3:1) solution and spread onto slides which were washed in PBS solution for $1 \mathrm{~min}$. Chromatin fibers were obtained by using an alkaline solution (0.07 M $\mathrm{NaOH}$ :ethanol, 5:2) and then fixed by adding a minimal amount of methanol. Slides were then air dried, dipped in a $70 \%, 95 \%$ and $100 \%$ ethanol series for 3 min each, air dried and stored at $4{ }^{\circ} \mathrm{C}$ until hybridization was carried out.

The probes used for fiber-FISH were obtained using a combination of two DAZ-specific cosmids, generously provided by Dr L.G. Brown, Massachusetts Institute of Technology, Cambridge (USA) (11). Cosmid 63C9 contains exons 2-11 spanning almost the entire sequence of the DAZ gene (GB accession number AC000021). Cosmid 46A6 contains exons 8-11 and extended for $35 \mathrm{~kb}$ downstream the 3 ' end of the DAZ gene (GB accession number AC000022). DNA probes were labeled by nick-translation with dUTPCy3 or dCTP-fluorX (Amersham, Milan, Italy).

The hybridization was carried out as previously reported (13). Briefly, DNA fibers were denatured treating each slide with a $70 \%$ formamide/2X SSC (pH 7.5) solution at $80^{\circ} \mathrm{C}$ for $2 \mathrm{~min}$; slides were then dipped in a $70 \%, 95 \%$ and $100 \%$ ethanol series for $3 \mathrm{~min}$ each and air dried. Probes were precipitated and denatured at $80^{\circ} \mathrm{C}$ for $8 \mathrm{~min}$, applied to the slides which were then covered with a coverslip and sealed with rubber cement. Hybridization occurred overnight in a dark humidified container at $37^{\circ} \mathrm{C}$, after which the coverslip was removed and the slides were immersed in a posthybridization wash of $50 \%$ formamide/2X SSC, 3 times at $37^{\circ} \mathrm{C}$ for $5 \mathrm{~min}$. Slides were then mounted in DAPI counterstain and antifade and stored in the dark at $4^{\circ} \mathrm{C}$, until microscope observation.

The fluorescent signals were evaluated using a Leica DMRXA2 microscope (Leica Microsystems SpA, Milan, Italy) equipped with a single filter-band for DAPI, FITC and $\mathrm{Cy} 3$ and a triple filter-band for the three fluorochromes and a digital camera. Camera control and image acquisition were carried out using the Q-fluor software (Leica).

Quantitative real-time PCR. The number of DAZ gene copies was determined by the TaqMan technology, which exploits the 5'-3' nucleolytic activity of the Ampli-Taq polymerase (15). The method uses the TaqMan probe which specifically anneals the template between the PCR primers. The comparative threshold cycle $\left(\mathrm{C}_{\mathrm{T}}\right)$ method $\left(\Delta \Delta \mathrm{C}_{\mathrm{T}}\right)$, which compares the amplification of the unknown sample (target) with that of a normalizer and a reference control (calibrator), was used to quantify the number of DAZ gene copies.

SRY single gene was chosen as the normalizer because of its localization within the Y chromosome. $\mathrm{C} 1$ was arbitrarily chosen as calibrator because he had 4 DAZ gene copies by $\mathrm{SFV}$ and fiber-FISH, as C2-C4, but he consistently showed the lowest threshold cycle variability.

Following the analysis of the GenBank sequence NG_004755, we chose an exon 6 probe which is repeated 3 times in DAZ1, once in DAZ 2 and DAZ3 and twice in DAZ4, as results from NCBI BLAST online software. Therefore, when all DAZ gene copies are present seven signals will be expected from quantitative real-time PCR.

DAZ gene probe consisted of 16 base pairs and contained 5'-fluor labeled VIC; it had the following sequence: 5'-(VIC)TCC TCC ACC ACA GTT T-MGB. DAZ gene primers had the following sequence: forward CAG CCA CGT CCT TTG 

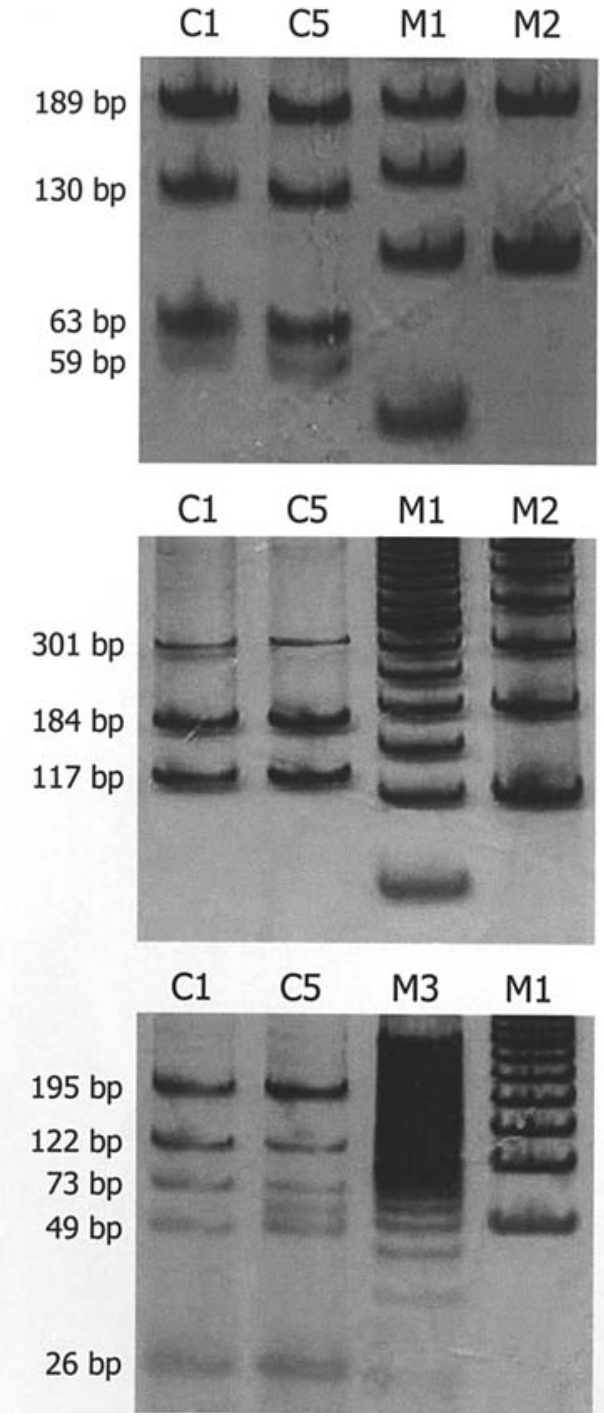

Figure 1. SFV analysis of patients $\mathrm{C} 1$ and C5. PCR amplification products are digested with the appropriate restriction enzymes and fragments are separated by $12 \%$ acrylamide gel electrophoresis. Upper panel: Sau3A digested sY581; middle panel: TaqI digested sY586; lower panel: DraI digested sY587. C1, normozoospermic subject, taken as control in real-time PCR analysis; C5, normozoospermic subject, who showed signal losses in real-time PCR analysis; M1, marker 50 bp; M2, marker 100 bp; M3, marker 10 bp.

GTA GTT AA; reverse GGA TTC CGC CAG ACG TTC T.

SRY gene probe consisted of 20 base pairs and contained a fluorescent reporter (FAM); it had the following sequence: 5'-(FAM)-TTT TTC AGG ACA GCA GTA GA-MGB. SRY gene primers had the following sequence: forward AAT TGG CGA TTA AGT CAA ATT CG; reverse TTG ACT ACT TGC CCT GCT GAT C. All probes and primers were purchased from Applera Italia (Monza, Italy).

The reaction mixture for DAZ and SRY real-time PCR was prepared in separate tubes as follows: $50 \mathrm{ng}$ of DNA, $1 \mathrm{X}$ TaqMan Universal PCR Master mix (Applera Italia), $200 \mathrm{nM}$ fluorogenic specific DAZ or SRY probe and $900 \mathrm{nM}$ of each specific primer, in a final volume of $50 \mu 1$.

The samples were assayed in quadruplicate in three different real-time PCR runs, using an ABI PRISM 7700 (Applied Biosystems/PE, Foster City, USA). After $2 \mathrm{~min}$ at $50^{\circ} \mathrm{C}$ followed by $2 \mathrm{~min}$ at $95^{\circ} \mathrm{C}$ to activate the polymerase, PCR was carried out as 40 cycles of $15 \mathrm{sec}$ at $95^{\circ} \mathrm{C}$ (denaturation) and $1 \mathrm{~min}$ at $60^{\circ} \mathrm{C}$ (annealing and extension).
The following formulas were applied to calculate the number of DAZ gene signals:

$$
\begin{gathered}
\Delta \mathrm{C}_{\mathrm{T}}=\mathrm{C}_{\mathrm{T}} \text { (target or calibrator) }-\mathrm{C}_{\mathrm{T}} \text { (normalizer) } \\
\Delta \Delta \mathrm{C}_{\mathrm{T}}=\Delta \mathrm{C}_{\mathrm{T}} \text { (target) }-\Delta \mathrm{C}_{\mathrm{T}} \text { (calibrator) } \\
\text { Number of DAZ signals }=2^{-\Delta \Delta \mathrm{CT}} \times 7
\end{gathered}
$$

Statistical analysis. Results are shown as mean \pm SEM. Coefficients of variation (CV) were calculated as ratio between standard deviation and mean number of signals for each man, multiplied by 100 .

\section{Results}

All subjects selected for this study had repeatedly normal sperm parameters and did not present any microdeletion of the AZF region as evaluated by qualitative PCR analysis. Moreover, none of them showed partial deletions of the DAZ gene cluster by SFV (Fig. 1).

Fiber-FISH confirmed the presence of 4 DAZ genes organized in two clusters with head-to-head orientation in subjects C1-C4. Surprisingly, C5 showed lack of one copy of the DAZ gene family (Fig. 2).

C1 was selected as a calibrator for quantitative real-time PCR and therefore the number of DAZ gene signals was set at 7. Subjects $\mathrm{C} 2-\mathrm{C} 4$ had a mean DAZ gene signal of $7.17 \pm 0.05$, whereas subject C5 had 5.35 \pm 0.05 DAZ gene signals (Table I). The lack of two signals in this man suggested the deletion of both DAZ2 and DAZ3 gene copies or of DAZ4 gene. The deletion of DAZ2 gene copy can, however, be ruled out because of the presence of the 301-bp fragment for sY586 which is specific for DAZ2. The mean CVs of DAZ gene signals were $1.5 \%, 0.7 \%, 1.6 \%$ and $1.8 \%$ for $\mathrm{C} 2$, C3, C4 and C5, respectively. The overall CV of the 4 subjects was $1.4 \pm 0.2 \%$.

\section{Discussion}

The present study was undertaken to develop a method to identify all possible partial DAZ gene deletions. SFV following amplification of sY581, sY586, sY587 was shown to be ineffective for this purpose, due to the limited number of markers generally used, which does not allow to fully distinguish the various fragments generated from the enzymatic digestion.

Therefore, an underestimation of the frequency of this chromosome abnormality among oligozoospermic or azoospermic patients may result (12).

In addition, it should be pointed out that SFV may in some cases be ineffective because of the reported polymorphic nature of the DAZ genes (12), recently shown to be due to $\mathrm{Y}-\mathrm{Y}$ gene conversion $(16,17)$.

Quantitative real-time PCR is a reproducible technique useful to study the DAZ region of the $\mathrm{Y}$ chromosome. It was able to detect partial deletions of the DAZ gene cluster in the case of the fertile man C5, where SFV failed to identify the abnormality. The deletion of C5 was confirmed by fiberFISH.

To develop this methodology, we decided to build a probe on exon 6 which, according to the DAZ gene sequence reported in GenBank (accession number NG_004755), is 

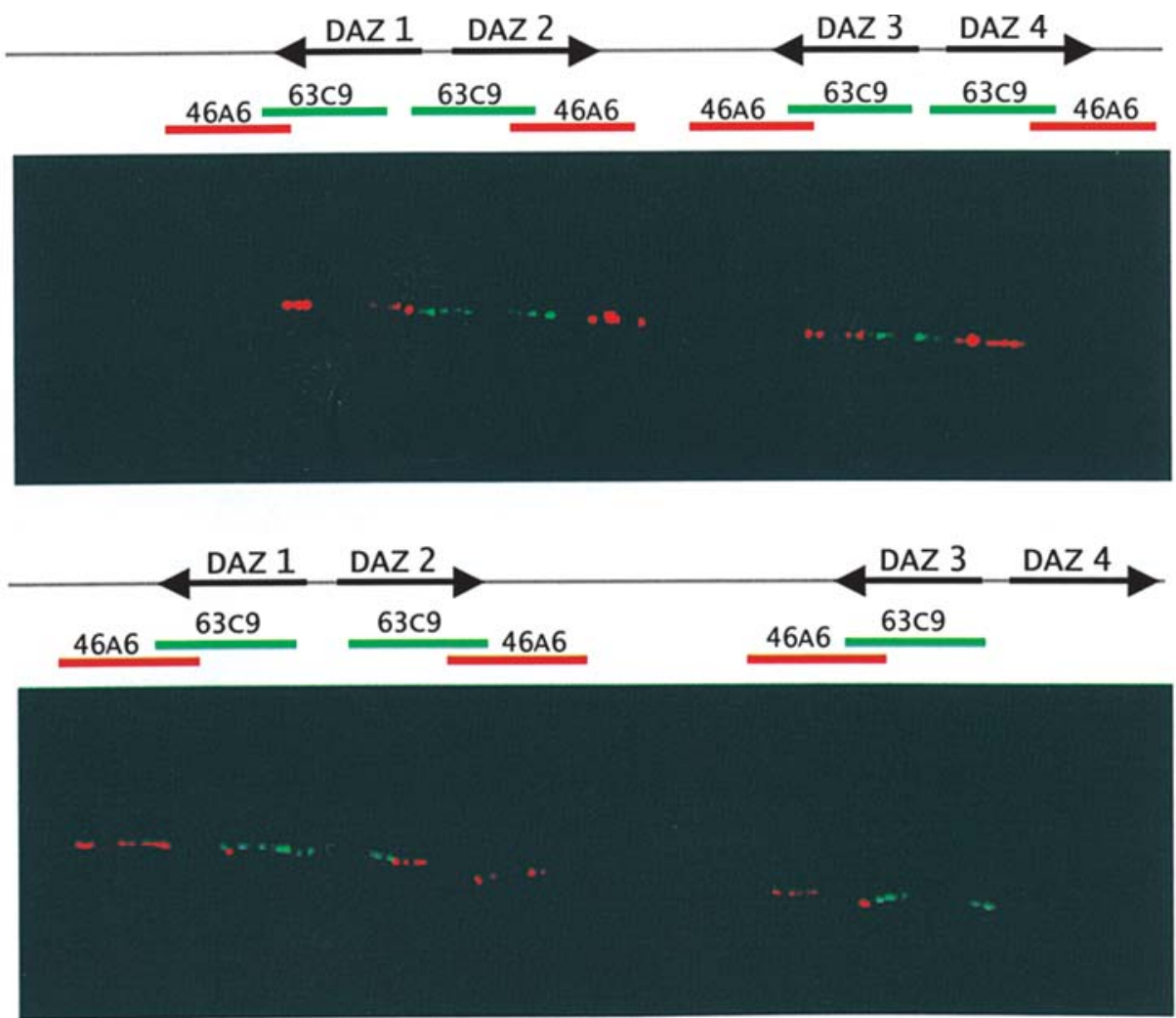

Figure 2. Fiber-FISH on extended DNA, obtained from subjects C1 and C5. Upper panel: subject C1, utilized as control, shows all 4 DAZ gene copies. Lower panel: the normozoospermic fertile C5 man presents only 3 fluorescent regions of the DAZ cluster.

Table I. Quantitative real-time PCR evaluation of the DAZ gene signals in 5 normozoospermic men.

\begin{tabular}{lllllll}
\hline ID & DAZ C $_{\mathrm{T}}{ }^{a}$ & $\mathrm{SRY} \mathrm{C}_{\mathrm{T}}{ }^{\mathrm{a}}$ & $\Delta \mathrm{C}_{\mathrm{T}}$ & $\Delta \Delta \mathrm{C}_{\mathrm{T}}$ & $2^{-\Delta \Delta C \mathrm{~T}}$ & No. of DAZ gene signals
\end{tabular}

Real-time PCR run 1

$\mathrm{H}_{2} \mathrm{O}$

Calibrator - $\mathrm{C} 1$

$\mathrm{C} 2$

C3

C4

C5

$40 \pm 0$
$20.17 \pm 0.07$
$19.25 \pm 0.10$
$19.29 \pm 0.46$
$20.32 \pm 0.12$
$22.51 \pm 0.11$

$\begin{array}{cc}40 \pm 0 & 0 \\ 22.50 \pm 0.10 & -2.33 \\ 21.60 \pm 0.10 & -2.35 \\ 21.63 \pm 0.15 & -2.35 \\ 22.70 \pm 0.09 & -2.38 \\ 24.49 \pm 0.02 & -1.97\end{array}$

$40 \pm 0$

$22.89 \pm 0.41$

$22.40 \pm 0.36$

$22.00 \pm 0.30$

$23.65 \pm 0.36$

$24.03 \pm 0.07$
0

$-2.49$

$-2.53$

$-2.53$

$-2.58$

$-2.08$
$21.94 \pm 0.23$

$\begin{array}{cll}0 & 0 & 0 \\ 0 & 1 & 7 \\ -0.02 & 1.01 & 7.08 \\ -0.02 & 1.01 & 7.08 \\ -0.05 & 1.03 & 7.20 \\ 0.36 & 0.78 & 5.46\end{array}$

C5

Real-time PCR run 3

$\mathrm{H}_{2} \mathrm{O}$
Calibrator $-\mathrm{C} 1$
$\mathrm{C} 2$
$\mathrm{C} 3$
$\mathrm{C} 4$
$\mathrm{C} 5$

$40 \pm 0$
$20.20 \pm 0.10$
$19.28 \pm 0.26$
$19.61 \pm 0.28$
$20.58 \pm 0.13$
$21.50 \pm 0.50$

$40 \pm 0$
$22.33 \pm 0.44$
$21.41 \pm 0.36$
$21.77 \pm 0.21$
$22.77 \pm 0.15$
$23.23 \pm 0.25$

0

$-2.13$

$-2.12$

$-2.16$

0
0
-0.04
-0.04
-0.09
0.41

0

1

1.03

1.03

1.06

0.75

\section{0

$\begin{array}{lll}0 & 0 & 0 \\ 0 & 1 & 7.00 \\ 0.01 & 1 & 6.97 \\ -0.03 & 1.02 & 7.13 \\ -0.06 & 1.04 & 7.28 \\ 0.40 & 0.76 & 5.32\end{array}$

${ }^{\mathrm{a}}$ Mean $\pm \mathrm{SD} ; \mathrm{C}_{\mathrm{T}}$, threshold cycle; $\Delta \mathrm{C}_{\mathrm{T}}$, difference between DAZ $\mathrm{C}_{\mathrm{T}}$ and SRY $\mathrm{C}_{\mathrm{T}}$ for each subject; $\Delta \Delta \mathrm{C}_{\mathrm{T}}$, difference between $\Delta \mathrm{C}_{\mathrm{T}}$ of $\mathrm{C} 2, \mathrm{C} 3, \mathrm{C} 4$ or $\mathrm{C} 5$ and $\Delta \mathrm{C}_{\mathrm{T}} \mathrm{C}$ 1. $\mathrm{C} 1$ was arbitrarily chosen as calibrator because he had 4 DAZ gene copies by SFV and fiber-FISH; he consistently has showed the lowest threshold cycle variability. The fertile normozoospermic man C5 has a partial deletion of the DAZ gene cluster, demonstrated by loss of two signals. 
repeated 3 times in DAZ1, once in DAZ2 and DAZ3 and twice in DAZ4.

Therefore, this particular DAZ probe may suggest which gene copy is deleted. Indeed, the loss of three signals more likely indicates the deletion of DAZ1 or DAZ3/DAZ4, the loss of two signals suggests the deletion of DAZ4 or DAZ2/ DAZ3 and the loss of one signal the deletion of DAZ2 or DAZ3.

After the description of the first case in a patient with oligozoospermia (18), partial deletions of the DAZ gene cluster have been reported in patients with impaired spermatogenesis $(12,19,20)$. Indeed, patients with oligozoospermia or azoospermia lack one or more DAZ gene copies with a frequency ranging from $4.3 \%$ to $9.1 \%$. These studies have not reported deletions in normozoospermic control men.

Recently, a case report showed that the deletion of 2 DAZ gene copies is still compatible with a normal spermatogenesis (21); this deletion was found in 5 infertile brothers with oligozoospermia or azoospermia and in their normozoospermic father.

More recently, a common variant of the Y chromosome lacking DAZ3/DAZ4 was reported demonstrating that these genes are not required for male fertility (22).

Surprisingly, Ferras and colleagues (23) found that 20 out of 50 fertile normozoospermic men (40\%) had a partial deletion of the DAZ gene cluster, in particular, lacking the DAZ4, suggesting that this gene copy may not play a relevant role during spermatogenesis (23).

By using a quantitative real-time PCR assay developed on DAZ exon 6, we have also found a normozoospermic fertile man (C5) with a partial deletion of the DAZ gene cluster since he had only 5 out of the 7 signals.

This deletion most probably involved the DAZ4 and not DAZ2 plus DAZ3 because in the latter case the deletion of DAZ would also be identified through SFV (sY586-TaqI).

Our observation adds further evidence that an intragenic DAZ deletion may be compatible with a normal spermatogenesis, as we have found in our patient C5 who had normal sperm parameters and was naturally fertile.

In conclusion, quantitative real-time PCR appears to be an effective and reproducible technique that can be used to study the genomic composition of the DAZ region. The probe chosen may give indications about the DAZ gene copy loss, which can be further proved by fiber-FISH.

The existence of a DAZ gene copy deletion in a normozoospermic patient suggests that not all DAZ gene copies may have the same role in human spermatogenesis and that partial deletions of this gene may be reported as a polymorphic deletion event in men with normal spermatogenesis.

\section{References}

1. Reijo R, Alagappan RK, Patrizio P and Page DC: Severe oligospermia resulting from deletions of azoospermia factor gene on Y chromosome. Lancet 347: 1290-1293, 1996.

2. Foresta C, Rossato M, Garolla A and Ferlin A: Male infertility and ICSI: are there limits? Hum Reprod 11: 2347-2348, 1996.

3. Affara NA: The role of the Y chromosome in male infertility. Expert Rev Mol Med 3: 1-16, 2001.

4. Kent-First MG, Kol S, Muallem A, Ofir R, Manor D, Blazer S, First $\mathrm{N}$ and Itskovitz-Eldor $\mathrm{J}$ : The incidence and possible relevance of Y-linked microdeletions in babies born after intracytoplasmic sperm injection and after infertile fathers. Mol Hum Reprod 2: 943-950, 1996.
5. Stuppia L, Calabrese G, Franchi PG, Mingarelli R, Gatta V, Palka G and Dallapiccola B: Widening of a Y-chromosome interval-6 deletion transmitted from a father to his infertile son accounts for an oligozoospermia critical region distal to the RBM1 and DAZ genes. Am J Hum Genet 59: 1393-1395, 1996.

6. Foresta C, Ferlin A, Garolla A, Moro E, Pistorello M, Barbaux S and Rossato M: High frequency of well defined Y-chromosome deletions in idiopathic Sertoli cell-only syndrome. Hum Reprod 13: 302-307, 1998.

7. Foresta C, Moro E and Ferlin A: Y chromosome microdeletion and alterations of spermatogenesis. Endocr Rev 22: 226-239, 2001.

8. Vogt PH, Edelmann A, Kirsch S, Henegariu O, Hirschmann P, Kiesewetter F, Kohn FM, Schill WB, Farah S, Ramos C, Hartmann M, Hartschuh W, Meschede D, Behre HM, Castel A, Nieschlag E, Weidner W, Grone HJ, Jung A, Engel W and Haidl G: Human Y chromosome azoospermia factors (AZF) mapped to different subregions in Yq11. Hum Mol Genet 5: 933-943, 1996.

9. Vogt PH and Fernandes S: Polymorphic DAZ gene family in polymorphic structure of AZFc locus: artwork or functional for human spermatogenesis? APMIS 111: 115-127, 2003.

10. Reijo R, Lee TY, Salo P, Alagappan R, Brown LG, Rosenberg M, Rozen S, Jaffe T, Straus D, Hovatta O, et al: Diverse spermatogenic defects in humans caused by Y chromosome deletions encompassing a novel RNA-binding protein gene. Nat Genet 10: 383-392, 1995.

11. Saxena R, De Vries JW, Alagappan RK, Skaletsky H, Brown LG, Ma P, Chen E, Hoovers JMN and Page DC: Four DAZ gene in two clusters found in the AZFc region of the human Y chromosome. Genomics 67: 256-267, 2000.

12. De Vries JWA, Hoffer MJV, Repping S, Hoovers JMN, Leschot $\mathrm{N}$ and van der Veen F: Reduced copy number of DAZ genes in subfertile and infertile men. Fertil Steril 77: 68-75, 2002.

13. Calogero AE, Garofalo MR, Barone N, De Palma A, Vicari E, Romeo R, Tumino S and D'Agata R: Spontaneuous regression over time of the germinal epithelium in a Y chromosome microdeleted patient. Hum Reprod 16: 1845-1848, 2001.

14. Fidlerova H, Senger G, Kost M, Sanseau P and Sheer D: Two simple procedures for releasing chromatin from routinely fixed cells for fluorescence in situ hybridisation. Cytogenet Cell Genet 65: 203-205, 1994.

15. Holland PM, Abramson RD, Watson R and Gelfand DH: Detection of specific polymerase chain reaction product by utilizing the $5^{\prime}$ to $3^{\prime}$ exonuclease activity of Thermus aquaticus DNA polymerase. Proc Natl Acad Sci USA 88: 7276-7280, 1991

16. Rozen S, Skaletsky H, Marszalek JD, Minx PJ, Cordum HS, Waterston RH, Wilson RK and Page DC: Abundant gene conversion between arms of palindromes in human and ape Y chromosome. Nature 423: 873-876, 2003.

17. Lepretre AC, Patrat C, Mitchell M, Jouannet $P$ and Bienvenu T: No partial DAZ deletions but frequent gene conversion events on the Y chromosome of fertile men. J Assist Reprod Genet 22: 141-148, 2005.

18. Moro E, Ferlin A, Yen PH, Franchi PG, Palka G and Foresta C: Male infertility caused by a de novo partial deletion of the DAZ cluster on the Y chromosome. J Clin Endocrinol Metab 85: 4069-4073, 2000.

19. Fernandes S, Huellen K, Goncalves J, Dukal H, Zeisler J, Rajpert De Meyts E, Skakkebaek NE, Habermann B, Krause W, Sousa M, Barros A and Vogt PH: High frequency of DAZ1/ DAZ2 gene deletions in patients with severe oligozoospermia. Mol Hum Reprod 8: 286-298, 2002.

20. Ferlin A, Bettella A, Tessari A, Salata E, Dallapiccola B and Foresta C: Analysis of the DAZ gene family in cryptorchidism and idiopathic male infertility. Fertil Steril 81: 1013-1018, 2004.

21. Gianotten J, Hoffer MJ, De Vries JW, Leschot NJ, Gerris J and van der Veen F: Partial DAZ deletions in a family with five infertile brothers. Fertil Steril 79: 1652-1655, 2003.

22. Fernandes S, Parrachini S, Meyer LH, Floridia G, Tyler-Smith C and Vogt PH: A large AZFc deletion removes DAZ3/DAZ4 and nearby genes from men in Y haplogroup N. Am J Hum Genet 74: 180-187, 2004.

23. Ferras C, Fernandes S, Marques CJ, Carvalho F, Alves C, Silva J and Sousa M: AZF and DAZ gene copy-specific deletion analysis in maturation arrest and Sertoli cell-only syndrome. Mol Hum Reprod 10: 755-761, 2004. 